\title{
DISPONIBILIDADE E QUALIDADE DA ÁGUA PARA IRRIGAÇÃO NO TERRITÓRIO INDÍGENA RIO FORMOSO, NA TRANSIÇÃO CERRADO/AMAZÔNIA, MATO GROSSO-BRASIL
}

Martins Toledo de Melo ${ }^{1}$ Tadeu Miranda de Queiroz ${ }^{2}$

Resumo: O objetivo deste trabalho foi quantificar e qualificar a água para a irrigação nos mananciais da Terra Indígena Rio Formoso em Tangará da Serra, Mato Grosso - Brasil, no contexto de importante polo agrícola brasileiro. Delimitaram-se cinco bacias hidrográficas com cinco pontos de coleta e amostragens em 12 meses seguidos, a partir de agosto/2016. Foram avaliadas 15 variáveis: nitrogênio $(\mathrm{N})$, fósforo $(\mathrm{P})$, temperatura $(\mathrm{T})$, turbidez $(\mathrm{Tu})$, sólidos totais $(\mathrm{ST})$, potássio $\left(\mathrm{K}^{+}\right)$, cálcio $\left(\mathrm{Ca}^{2+}\right)$, magnésio $\left(\mathrm{Mg}^{2+}\right)$, cloretos $\left(\mathrm{Cl}^{-}\right)$, bicarbonatos $\left(\mathrm{HCO}_{3}\right)$, condutividade elétrica (CE), potencial hidrogeniônico $(\mathrm{pH})$, coliformes termotolerantes (C.T.), alcalinidade (Alc) e sódio ( $\mathrm{Na}^{+}$) e calculada a razão de absorção de sódio (RAS) e a dureza (Du GHF). Os resultados revelaram risco nulo de salinização, toxidade e risco severo de sodificação. O potencial hidrogeniônico é baixo e a temperatura da água ficou acima de $25 \stackrel{\circ}{\circ}$. A concentração de coliformes termotolerantes em três pontos prejudica 0 cultivo de folhosas que são consumidas cruas. As desconformidades encontradas indicam que o uso da água deve ser feito com acompanhamento técnico especializado para evitar danos irreversíveis ao solo e equipamentos. Não há limitação de quantidade de água com vazão disponível outorgável de $1,884 \mathrm{~m}^{3} \mathrm{~s} \mathrm{~s}^{-1}$.

Palavras-chave: Chapadão dos Parecis. Haliti-Paresí. Salinidade. Sodicidade. Recursos hídricos.

\section{AVAILABILITY AND WATER QUALITY FOR IRRIGATION IN RIO FORMOSO INDIGENOUS TERRITORY, IN THE TRANSITION OF CERRADO/AMAZON, MATO GROSSO, BRAZIL}

Abstract: The aim of this study was to quantify and qualify the water for irrigation in the watershed of Rio Formoso Indigenous Land in Tangara da Serra, Mato Grosso, Brazil, in the condition of an important Brazilian agricultural center. Five river basins were delineated with five collection points and sampling in 12 consecutive months, starting in August / 2016. The following 15 variables were evaluated: nitrogen (N), phosphorus $(\mathrm{P})$, temperature $(\mathrm{T})$, turbidity $(\mathrm{Tu})$, total solids $(\mathrm{TS})$, potassium $\left(\mathrm{K}^{+}\right)$, calcium $\left(\mathrm{Ca}^{2+}\right)$, magnesium $\left(\mathrm{Mg}^{2+}\right)$, chlorides $\left(\mathrm{Cl}^{-}\right)$, bicarbonates $\left(\mathrm{HCO}_{3}^{-}\right)$, electrical conductivity (EC), potential of hydrogen $(\mathrm{pH})$, thermotolerant coliforms (T.C.), alkalinity (Alk) and sodium $\left(\mathrm{Na}^{+}\right)$and the ratio of sodium absorption (RSA) and hardness (Har GHF) was calculated. The results revealed no risk of salinization, toxicity and severe risk of sodification. The potential of hydrogen is low and the water temperature is above $25^{\circ} \mathrm{C}$. The concentration of thermotolerant coliforms at three points damages the cultivation of hardwoods that are consumed raw. The disconformities found indicate that the water use should be done with specialized technical assistance to avoid irreversible damage to the soil and equipments. There is no limitation of water quantity of available flow grantable of $1,884 \mathrm{~m}^{3} \mathrm{~s}^{-1}$.

Keywords: Chapadão dos Parecis. Haliti-Paresí. Salinity. Sodicity. Water resources.

\footnotetext{
1 Universidade do Estado de Mato Grosso - UNEMAT, PPGASP, Tangará da Serra, Brasil, toledo_martins@hotmail.com, http://orcid.org/0000-0002-1149-6780

2 Universidade do Estado de Mato Grosso - UNEMAT, Depto. Eng. Produção Agroindustrial, Barra do Bugres, Brasil, tdmqueiroz@unemat.br, https://orcid.org/0000-0002-1959-7658
} 


\section{DISPONIBILIDAD Y CALIDAD DEL AGUA PARA IRRIGAÇÃO EM EL TERRITÓRIO INDÍGENA RIO FORMOSO, EM LA TRANSICIÓN SIERRA/AMAZONAS, MATO GROSSO-BRASIL}

Resumen: El objetivo de este trabajo fue cuantificar y calificar el agua para la irrigación en los manantiales de la tierra indígena Rio Formoso en Tangará da Serra, Mato Grosso-Brasil, en el contexto de importante polo agrícola brasileño. Se delimitaron cinco cuencas hidrográficas con cinco puntos de recolección y muestreos en 12 meses seguidos, a partir de agosto / 2016. Fueron evaluadas 15 variables: nitrógeno $(\mathrm{N})$, fósforo $(\mathrm{P})$, temperatura $(\mathrm{T})$, turbiedad $(\mathrm{Tu})$, sólidos totales $(\mathrm{ST})$, potásio $\left(\mathrm{K}^{+}\right)$, cálcio $\left(\mathrm{Ca}^{2+}\right)$, magnésio $\left(\mathrm{Mg}^{2+}\right)$, cloruros $(\mathrm{Cl}-)$, bicarbonatos $\left(\mathrm{HCO}_{3}{ }^{-}\right)$, conductividad eléctrica (CE), potencial hidrogeniónico $(\mathrm{pH})$, coliformes termotolerantes (C.T.), alcalinidad (Alc) y sódio $\left(\mathrm{Na}^{+}\right)$, y calculada la razón de la absorción de sódio (RAS) y la dureza (Du GHF). Los resultados revelaron riesgo nulo de salinización, toxicidad y riesgo severo de sodificación. El potencial hidrogeniónico es bajo y la temperatura del agua se mantuvo arriba de $25^{\circ} \mathrm{C}$. La concentración de coliformes termotolerantes en tres puntos perjudica el cultivo de hojas que son consumidas crudas. Las disfunciones encontradas indican que el uso del agua debe ser realizado con acompañamiento técnico especializado para evitar daños irreversibles al suelo y equipamientos. No hay limitación de cantidad de agua con caudal disponible de $1,884 \mathrm{~m}^{3} \mathrm{~s}^{-1}$.

Palabras-clave: Chapadão dos Parecis. Haliti-Paresí. Salinidade. Sodicidad. Recursos hídricos.

\section{Introdução}

Para atender a demanda mundial de alimentos utiliza-se a produção agrícola em alta escala, muitas vezes priorizando o ganho econômico em detrimento dos recursos naturais utilizados para a produção (REIS et al., 2016). O estado de Mato Grosso - Brasil tem contribuído com $28,0 \%$ da produção nacional de cereais, além de $67,5 \%$ de todo o algodão produzido no país (IBGE, 2019).

A expansão do agronegócio no Centro-Oeste brasileiro alcançou as fronteiras das terras indígenas e em alguns locais avançou para dentro delas modificando o sistema produtivo tradicional. $\mathrm{Na}$ Chapada dos Parecis o processo de ocupação da terra e a produção por não indígenas intensificou-se a partir de 1978, com a derrubada do cerrado para a implantação de lavouras mecanizadas e áreas de pastagens (SIEBERT; VECCHIATO; FERNANDO, 2014), fato que reduziu a vegetação nativa afetando os indígenas que estão com uma área de agricultura tradicional de coleta e caça limitada, o que os induz a buscarem formas alternativas de alimento.

Em contrapartida, os indígenas além das atividades tradicionais, já praticam a agricultura de monocultura de alta tecnologia em parceria com não indígenas na Terra Indígena Rio Formoso (TIRF) com o cultivo de soja e milho safrinha (TERÇAS 
et al., 2016), fato que demonstra do lado dos indígenas implementação da produção, a busca por renda alternativa, a incorporação de tecnologias e a disponibilidade para adoção de novas técnicas de produção.

Na parceria, a parte da produção de milho e soja que cabe aos índios é convertida em dinheiro e aplicada, muitas vezes, em bens de consumo não alimentares como carro, eletrodomésticos, entre outros. Além disso, o rateio dos dividendos não é igualitário, nem proporcional, o que deixa parte dos índios em situação de vulnerabilidade. Contrapondo à situação, foi proposto pelas associações indígenas e as duas cooperativas criadas nas aldeias e executado com metodologia pedagógica do Instituto Federal de Ensino de Tangará da Serra/MT e Campo Novo do Parecis/MT, com participação da Fundação Nacional do Índio (FUNAl) e a ONG The Nature Conservancy (TNC), um curso voltado para a gestão dos recursos iniciado e finalizado no segundo semestre de 2019.

Nas aldeias, o planejamento das atividades agrícolas utilizando a irrigação tanto na agricultura tradicional quanto na área de agricultura moderna, poderia aumentar a produtividade e melhorar a renda para a comunidade oportunizando a produção de alimentos tradicionais o ano todo. Isso teria impacto significativo para melhoria da qualidade de vida dos índios e na segurança alimentar na comunidade, evitando-se quadros de fome e desnutrição conforme reportado por Santos et al. (2018).

A irrigação é uma técnica que permite maior segurança nos cultivos, diversificação da produção, produção na entressafra, entre outras vantagens. Todavia, requer estudos de implantação para melhor escolha do método e sistema de irrigação e com o mesmo grau de importância, porém com menor difusão estão os estudos preliminares de avaliação da qualidade da água para irrigação e de sua disponibilidade para uso.

A água imprópria para a agricultura além de contaminar, poderá degradar o solo pela salinização, a sodicidade, intoxicar as plantas, corroer e entupir tubulações inviabilizando a produção agrícola, ainda pode acarretar a contaminação dos usuários diretos e indiretos (ALMEIDA, 2010) e ainda reduzir lucros e até mesmo inviabilizar a atividade.

Estudos de qualidade de água para irrigação têm sido realizados em países áridos e semiáridos com o Egito, a Líbia, Tunísia, Argélia, Marrocos, Síria, Malta e Líbano (BORTOLINI; MAUCIERI; BORIN, 2018). No Brasil, especialmente na região nordeste do país (VASCONCELOS et al., 2009), mas também em outras regiões 
brasileiras (REIS et al., 2011) e até em Mato Grosso (QUEIROZ; MELO; FERREIRA, 2018).

Pelas características da região, a qual se encontra na transição entre os biomas Cerrado e Amazônia, com ocorrência de diversos cursos d'água, espera-se encontrar água em abundância e de boa qualidade para irrigação.

Neste contexto, a presente pesquisa teve por objetivo quantificar e qualificar a água para a irrigação na TIRF comunidade Haliti-Paresí em Tangará da Serra/MT. Cabe destacar que esse estudo é inédito e pioneiro para o caso das terras dos índios agricultores do Brasil e servirá de norteamento para implantação de tecnologias de produção agrícola permitindo um melhor planejamento estratégico da produção agrícola, além de contribuir para conhecimento científico brasileiro.

\section{Material e métodos}

Este trabalho foi realizado com autorização da Fundação Nacional do Índio FUNAI (Autorização № 036/AAEP/PRES/2016 de 28/06/2016), mediante a concordância da comunidade e parecer $A d$ hoc reconhecendo o mérito científico pelo Conselho Nacional de Desenvolvimento Científico e Tecnológico- CNPq.

\section{Caracterização da área de estudo}

A área de estudo é habitada pela comunidade indígena Haliti-Paresí a qual é designada de Terra Indígena Rio Formoso e está localizada no município de Tangará da Serra, estado de Mato Grosso - Brasil, onde desenvolvem suas atividades tradicionais e econômicas. Figura 1.

Figura 1 - A. Vista aérea da aldeia; B. Preparativos para festas e C. Capacitação à agricultura mecanizada

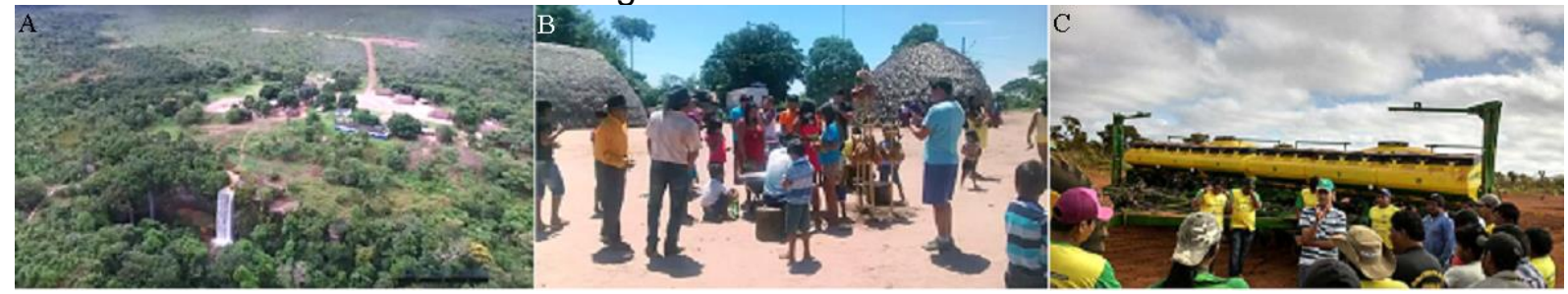

Fonte: A-https://scontent-gru2-1.xx.fbcdn.net/. B-Reprodução/TVCA. C-https://scontent-gru21.xx.fbcdn.net

Ainda, caracteriza-se pelas cabeceiras que formam o rio Formoso e parte do curso do rio Juba em Tangará da Serra/MT, ambos afluentes da margem direita do rio Sepotuba, um dos formadores do Pantanal mato-grossense, que com o rio Paraná e Uruguai formam a bacia platina. A TIRF está na bordadura do chapadão 
dos Parecis, um dos principais polos agropecuário do estado do Mato Grosso na produção de carne, cereais e algodão.

As bacias hidrográficas apresentadas na Figura 2 foram delimitadas remotamente utilizando-se de imagens do Projeto Topodata - imagens préprocessadas com resolução de 30m (INPE, 2018) e utilizou-se o software QGIS versão 2.18.15 com o auxílio da ferramenta TauDEM, ainda foi necessário a retroprojeção das coordenadas para o Datun Sirgas 2000/UTM que é o Sistema Geodésico de Referência oficial do País, zone 21, EPSG: 31981(SANTOS, 2018).

A base cartográfica referente ao município e estado federados, obteve-se no site do IBGE (IBGE, 2017) e os limites da TIRF no site FUNAI (FUNAI, 2018).

Figura 2 - Área de estudo com relação ao município de Tangará da Serra/MT, Brasil

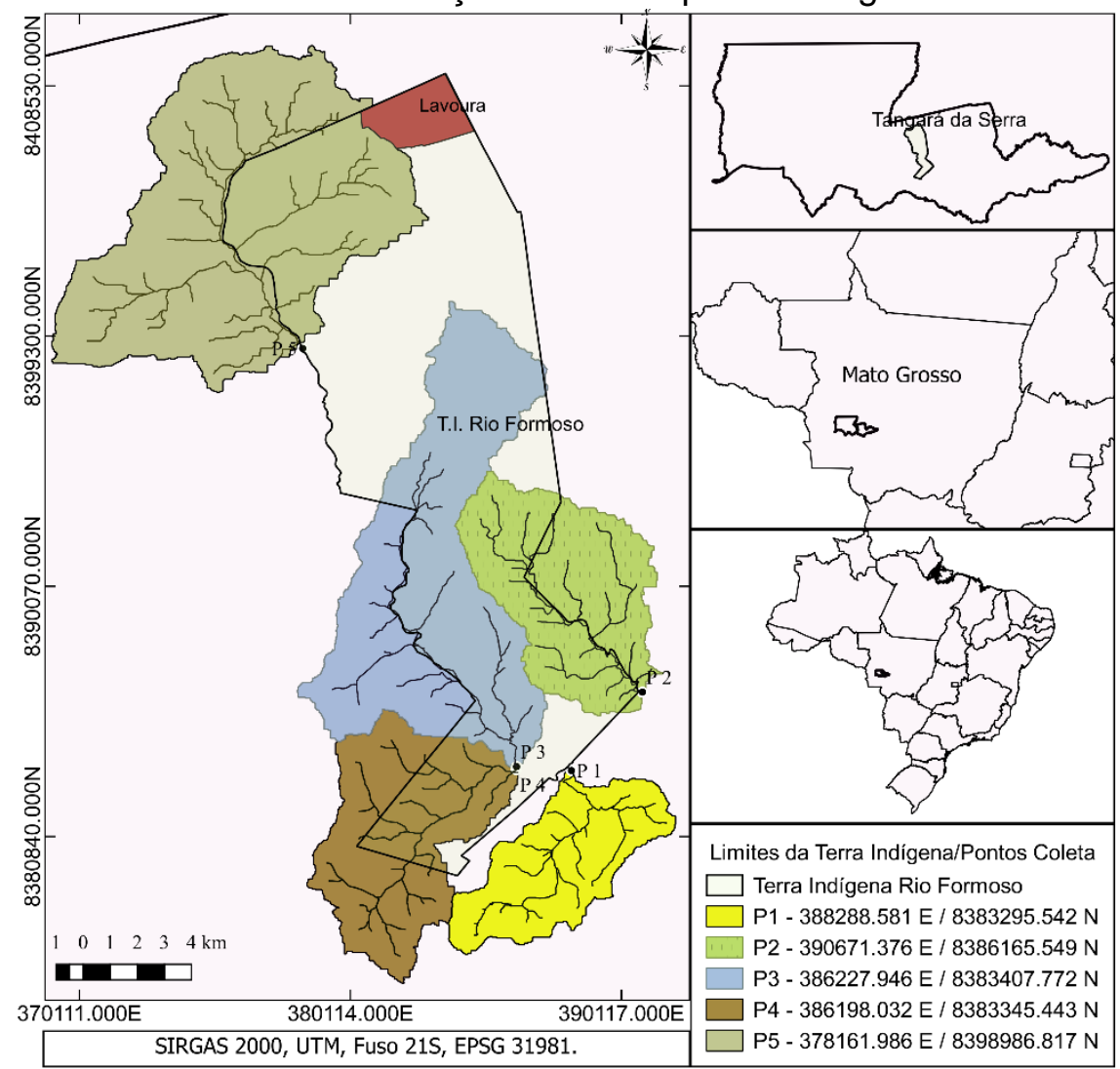

Fonte: Elaborado pelos autores (2017)

Os pontos de coletas representam o exutório de todas as bacias hidrográficas da TIRF e que foram caracterizadas como: P1 - riacho Anta: bacia limítrofe a TIRF, roças em pousio a jusante e floresta transformada em pastagens, tributário do rio Fomroso; P2 - rio Formoso: bacia limítrofe à TIRF, roças indígenas a montante, floresta lado direito e pastagem lado esquerdo; P3 - riacho Bonito: roças indígenas a montante e jusante, aldeia distante em $3 \mathrm{~km}$ a montante, área de cerrado e exutório em floresta preservada, tributário do rio Formoso; P4 - riacho Ararinha: com 
nascente no cerrado preservado e o exutório na floresta preservada, roças indígenas a jusante, tributário do rio Formoso; P5 - rio Juba: bacia limítrofe à TIRF, abastecimento da aldeia Santa Vitalina, roças indígenas a montante e jusante, com cerrado preservado, porém, a direita um tributário com mata ciliar desmatada.

Quanto aos regimes pluviométricos, são caracterizados por uma estação chuvosa compreendida de outubro a abril e uma seca entre maio e setembro (RAMOS et al., 2017). No município de Tangará da Serra/MT o clima é quente o ano todo com temperatura média de $24,4^{\circ} \mathrm{C}$ e umidade relativa do ar entre 70 e $80 \%$, com precipitação pluviométrica de $1.500 \mathrm{~mm}$, caracterizando clima tropical úmido megatérmico (AW) pela classificação de Köppen, conforme Dallacort et al. (2010).

A estimativa da evapotranspiração potencial (ETo) da região com dados médios do período 2003 a 2010 chega ao valor de 1.310,3 mm anuais, com déficit hídrico nos meses de abril até outubro, sendo que a ETo máxima mensal no mês de outubro foi de $128,5 \mathrm{~mm}$ e a mínima mensal foi de $79,08 \mathrm{~mm}$ no mês de julho (DALLACORT et al., 2010). E, conforme reportam Fenner et al. (2014) a partir de julho a capacidade de armazenamento de água no solo diminuiu, perdurando até a estabilização das chuvas no mês de novembro, período em que há uma maior demanda de água para as plantas.

\section{Determinação da vazão dos cursos d'água}

A vazão disponível outorgável, conforme a legislação do Estado de Mato Grosso foi estimada como sendo 70\% da vazão medida (MATO GROSSO, 2017).

Neste trabalho, foi estimada pela regionalização hidrológica com dados que estão disponíveis no site: https://monitoramento.sema.mt.gov.br/simlam/\# (MATO GROSSO, 2017) Esse procedimento tem respaldo no trabalho de Silveira, Tucci e Silveira (1998) que orienta a possibilidade de ser utilizada em bacias sem dados a amostragem reduzida de vazões em período de descarga do aquífero, como parâmetro semelhante à vazão garantida em 95\% do tempo.

Contudo foram feitas medidas da vazão utilizando-se do método clássico do flutuador (Azevedo Netto et al., 1998) em uma única aferiação nos pontos P1, P3, P4 e P5, (out/17) e no ponto P2 utilizou-se a vazão medida por Seiva (2017) com uso de um molinete fluviométrico em julho de 2014, objetivando comparar com os dados disponíveis da regionalização hidrográfica. 


\section{Coletas, análises e avaliações}

As campanhas de coleta das amostras de água foram mensais no período de set/2016 à ago/2017, buscando realizá-las sempre próximo ao dia 15 de cada mês (ALMEIDA, 2010).

As coletas, conservação, transporte e análise das amostras de água obedeceram aos procedimentos descritos no Standard Methods for Examination of Water and Wastewater (APHA, 2005) e foram avaliadas no Laboratório de Qualidade de Água (LaQuA) no Campus de Barra do Bugres da Universidade do Estado de Mato Grosso (UNEMAT).

As variáveis avaliadas e suas respectivas simbologias e metodologias, conforme APHA (2005), são: nitrogênio ( $N-4500 N-B)$, fósforo (P-4500P-B e E), temperatura (T-2550), turbidez (Tu-2130 B), sólidos totais (ST-2540 C), potássio ( $\mathrm{K}^{+}-$ 3500-K B), cálcio ( $\left.\mathrm{Ca}^{2+}-3500 \mathrm{Ca}-\mathrm{B}\right)$, magnésio $\left(\mathrm{Mg}^{2+-} 3500 \mathrm{Mg}^{-} \mathrm{B}\right)$, cloretos $\left(\mathrm{Cl}^{-}-4500\right.$ $\mathrm{Cl}-\mathrm{B})$, bicarbonatos $\left(\mathrm{HCO}_{3}-2320 \mathrm{~B}\right)$, condutividade elétrica (CE-2510 B), potencial hidrogeniônico $(\mathrm{pH}-4500 \mathrm{H})$, coliformes termotolerantes (C.T-9223 B), alcalinidade (Alc), sódio ( $\mathrm{Na}^{+}-3500-\mathrm{Na} \quad$ B) e ainda foi calculada a razão de absorção de sódio (RAS) e a dureza em Graus Hiditimétricos Frances (GHF), conforme Almeida (2010).

As amostras para sódio $\left(\mathrm{Na}^{+}\right)$e potássio $\left(\mathrm{K}^{+}\right)$foram congeladas e posteriormente analisadas no Centro de Pesquisas, Estudos e Desenvolvimento Agro-Ambientais (CEPEDA) do Campus de Tangará da Serra da UNEMAT.

Os dados foram analisados no software Action e as médias comparadas utilizando o teste Scott-Knott ao nível de significância de 5\%.

Os resultados de salinidade foram interpretados conforme classificação do Laboratório de Salinidade dos Estados Unidos (RICHARDS, 1954), Ayers \& Westcot (1991) e Almeida (2010), entre outras publicações científicas sobre o assunto.

Quanto as espécies cultivadas e passíveis de irrigação e utilizados pela comunidade indígena, tem como principais as seguintes: banana, mandioca, batata doce, cará da terra, milho, soja, arroz, melancia, hortaliça folhosas.

\section{Resultados e discussão}

A quantidade de água produzida pelas bacias e disponíveis nos corpos de água, nos pontos avaliados, bem como a área de cada bacia hidrográfica, está apresentada na Tabela 1. 
Tabela 1 - Área delimitada da bacia hidrográfica (A) e vazão medida (Q) em cada um dos corpos de água e vazão disponível outorgável ( $\left.Q_{\text {disp }}\right)$

\begin{tabular}{|c|c|c|c|c|c|}
\hline \multirow{2}{*}{ Ponto de Coleta } & \multirow{2}{*}{ A (ha) } & \multicolumn{2}{|c|}{ Medida empírica } & \multicolumn{2}{|c|}{$\begin{array}{l}\text { Regionalização de } \\
\text { vazões }\end{array}$} \\
\hline & & $Q\left(m^{3} s^{-1}\right)$ & $Q_{\text {disp }}\left(m^{3} \mathrm{~s}^{-1}\right)$ & $Q\left(m^{3} s^{-1}\right)$ & $Q_{\text {disp }}\left(\mathrm{m}^{3} \mathrm{~s}^{-1}\right)$ \\
\hline P1: Riacho Anta & 2.856 & 0,12 & 0,08 & 0,398 & 0,279 \\
\hline P2: Rio Formoso & 4.269 & 19,38 & 13,56 & 0,664 & 0,465 \\
\hline P3: Riacho Bonito & 7.784 & 5,06 & 3,54 & 1,017 & 0,712 \\
\hline P4: Riacho Ararinha & 4.317 & 1,67 & 1,17 & 0,612 & 0,428 \\
\hline P5: Rio Juba & 10.353 & 4,57 & 0,06 & 1,401 & $-0,056$ \\
\hline Total & 29,579 & 30,80 & 18,41 & 4,092 & 1,884 \\
\hline
\end{tabular}

A vazão medida no mês de julho de 2014 do P2 e a vazão medida em out/2017 nos demais pontos apresentou resultados muito superiores à estimativa da vazão regionalizada para o mês de outubro. Resultado semelhante com vazões estimadas superiores às vazões medidas foi reportado por Oliveira, Derlan e Queiroz (2018) na bacia hidrográfica do rio Branco, no município de Barra do Bugres/MT, mostrando a importância de aferições de campo, quando possível, a fim de se ter uma noção mais exata da vazão, uma vez que, as estimativas disponíveis estão superestimando a vazão.

Tomando dados da Estação Pluviométrica (Código:01457004) da Agência Nacional de Águas aferiu-se que a precipitação anual da região, no período de 2014 a 2017, variou entre 1469 mm (2017) e 1805 (2016) com média de 1643 mm e coeficiente de variação de 10,45\%. Esses resultados mostram a variação das chuvas na região com impacto na oferta de água dos mananciais.

Nas bacias avaliadas não há estação de monitoramento, assim, o comportamento hidrológico é desconhecido, o que torna os resultados deste trabalho pioneiro, embora seja preliminar e não conclusivo, requerendo para maiores detalhes, novos estudos mais completos e abrangentes.

No P2, mesmo com uma concessão de captação/diluição insignificante a montante de $0,0014 \mathrm{~m}^{3} \mathrm{~s}^{-1}$ mantém $70 \%$ outorgável) e estão projetadas três pequenas centrais elétricas a jusante ( $\mathrm{PCHs}$ ), assim como os pontos: P1, P3 e P4; a jusante do P5 há instalações de PCHs e hidrelétricas e a montante não há outorga, contudo, na regionalização da vazão há o déficit para o mês de outubro (MATO GROSSO, 2017). 
Os resultados das variáveis físicas, químicas e microbiológicas dos cinco pontos, individualizados entre os períodos seco e chuvoso, estão apresentados na Tabela 2 de onde se observa também o valor de referência para cada variável.

Tabela 2 - Variáveis físicas, químicas e microbiológica avaliadas nos períodos seco/chuvoso e os parâmetros para a irrigação de cada variável.

\begin{tabular}{|c|c|c|c|c|c|c|c|c|}
\hline \multirow{2}{*}{ Variáveis } & \multirow{2}{*}{ Unid. } & \multirow{2}{*}{ Período } & \multicolumn{5}{|c|}{ Pontos avaliados } & \multirow{2}{*}{ Parâmetro } \\
\hline & & & P1 & $\mathrm{P} 2$ & P3 & P4 & P5 & \\
\hline \multirow{2}{*}{$\mathrm{Ca}^{2+}$} & \multirow{2}{*}{$\left(\right.$ mmolc $\left.L^{-1}\right)$} & Seco & $0,438 \mathrm{~b}$ & $\mathrm{NQ}$ & $\mathrm{NQ}$ & NQ & $\mathrm{NQ}$ & \multirow{2}{*}{$0-20$} \\
\hline & & Chuva & $0,557 \mathrm{a}$ & $N Q$ & $N Q$ & $N Q$ & $N Q$ & \\
\hline \multirow{2}{*}{$\mathrm{Mg}^{2+}$} & \multirow{2}{*}{$\left(\mathrm{mmolc} \mathrm{L}^{-1}\right)$} & Seco & $0,018 b$ & $N Q$ & $N Q$ & $\mathrm{NQ}$ & $N Q$ & \multirow{2}{*}{$0-5$} \\
\hline & & Chuva & $0,044 \mathrm{a}$ & $N Q$ & $N Q$ & $0,004 \mathrm{c}$ & $0,005 \mathrm{c}$ & \\
\hline \multirow{2}{*}{$\mathrm{Na}^{+}$} & \multirow{2}{*}{$\left(\mathrm{mmolc} \mathrm{L}^{-1}\right)$} & Seco & $0,032 \mathrm{a}$ & $0,001 \mathrm{c}$ & $N Q$ & $0,001 \mathrm{c}$ & $N Q$ & \multirow{2}{*}{$0-40$} \\
\hline & & Chuva & $0,011 \mathrm{~b}$ & $0,001 \mathrm{c}$ & $0,001 \mathrm{c}$ & $0,001 \mathrm{c}$ & $0,001 \mathrm{c}$ & \\
\hline \multirow{2}{*}{ RAS } & $\left(\left(\mathrm{mmol} \mathrm{L}^{-}\right.\right.$ & Seco & $0,07 \mathrm{a}$ & - & - & - & - & \multirow{2}{*}{$0-15$} \\
\hline & $\left.\left.{ }^{1}\right)^{0,5}\right)$ & Chuva & $0,02 \mathrm{~b}$ & - & - & - & - & \\
\hline \multirow{2}{*}{ Du (GHF) } & \multirow{2}{*}{$\left(\mathrm{mg} \mathrm{L}^{-1}\right)$} & Seco & $2,28 b$ & - & - & - & - & \multirow{2}{*}{$<7$} \\
\hline & & Chuva & $3,01 \mathrm{a}$ & - & - & - & - & \\
\hline \multirow{2}{*}{ CE } & \multirow{2}{*}{$\left(\mathrm{dS} \mathrm{m} \mathrm{m}^{-1}\right)$} & Seco & $0,064 \mathrm{a}$ & $0,002 \mathrm{c}$ & $0,004 \mathrm{c}$ & $0,003 \mathrm{c}$ & $0,003 \mathrm{c}$ & \multirow{2}{*}{$0-3$} \\
\hline & & Chuva & $0,042 \mathrm{~b}$ & $0,002 \mathrm{c}$ & $0,002 \mathrm{c}$ & $0,005 \mathrm{c}$ & $0,003 \mathrm{c}$ & \\
\hline \multirow{2}{*}{$\mathrm{pH}$} & \multirow{2}{*}{ - } & Seco & $7,25 \mathrm{a}$ & $6,85 a$ & $5,95 \mathrm{~b}$ & $6,07 \mathrm{~b}$ & $5,36 \mathrm{c}$ & \multirow{2}{*}{$6,5-8,4$} \\
\hline & & Chuva & $7,05 \mathrm{a}$ & $6,06 \mathrm{~b}$ & $5,81 \mathrm{~b}$ & $6,31 \mathrm{~b}$ & $5,14 \mathrm{c}$ & \\
\hline \multirow{2}{*}{ Alc } & \multirow{2}{*}{ (mg L-1) } & Seco & $16,04 \mathrm{a}$ & $4,34 \mathrm{~b}$ & $2,89 \mathrm{~b}$ & $3,03 \mathrm{~b}$ & $2,97 \mathrm{~b}$ & 500 \\
\hline & & Chuva & $15,28 \mathrm{a}$ & $4,56 \mathrm{~b}$ & $4,88 \mathrm{~b}$ & $4,96 \mathrm{~b}$ & $4,22 \mathrm{~b}$ & \\
\hline Nlno & $(m \mathrm{l}$ & Seco & 0,004 & 0,001 & 0,001 & 0,002 & 0,001 & 010 \\
\hline IV IIS & (ming L ) & Chuva & 0,004 & 0,001 & 0,002 & 0,003 & 0,002 & $0-10$ \\
\hline P nc & $(\mathrm{mg}$ & Seco & 0,007 & 0,002 & 0,002 & 0,002 & 0,003 & 0 \\
\hline (110 & (ing & Chuva & 0,005 & 0,004 & 0,003 & 0,005 & 0,003 & 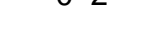 \\
\hline$K+$ & $\left(m a^{-1}\right)$ & Seco & $0,043 \mathrm{a}$ & $N Q$ & $0,001 \mathrm{c}$ & $0,001 \mathrm{c}$ & $N Q$ & $0=$ \\
\hline$\pi$ & (ming & Chuva & $0,030 \mathrm{~b}$ & $0,001 \mathrm{c}$ & $0,001 \mathrm{c}$ & $0,002 \mathrm{c}$ & $N Q$ & $u-c$ \\
\hline & & Seco & $0,09 \mathrm{~b}$ & $0,27 \mathrm{a}$ & $0,14 b$ & $0,10 \mathrm{~b}$ & $0,15 b$ & \\
\hline r & 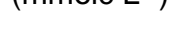 & Chuva & $0,10 \mathrm{~b}$ & $0,22 \mathrm{a}$ & $0,16 \mathrm{~b}$ & $0,12 b$ & $0,18 \mathrm{~b}$ & \\
\hline $\mathrm{HCO}^{-}$ & $(\mathrm{mmolc}$ & Seco & $0,28 a$ & $0,06 \mathrm{~b}$ & $0,06 \mathrm{~b}$ & $0,06 \mathrm{~b}$ & $0,05 \mathrm{~b}$ & $0-10$ \\
\hline 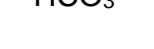 & & Chuva & $0,29 a$ & $0,08 \mathrm{~b}$ & $0,08 \mathrm{~b}$ & $0,09 \mathrm{~b}$ & $0,07 \mathrm{~b}$ & (0. \\
\hline$T_{1}$ & (UINT) & Seco & $26,68 \mathrm{a}$ & $0,49 \mathrm{~b}$ & $0,60 \mathrm{~b}$ & $0,93 \mathrm{~b}$ & $0,88 \mathrm{~b}$ & 100 \\
\hline 10 & (0) & Chuva & $32,48 \mathrm{a}$ & $1,74 \mathrm{~b}$ & $1,11 \mathrm{~b}$ & $2,67 b$ & $1,83 b$ & 100 \\
\hline ST ns & $\left(m a^{-1}\right)$ & Seco & 0,37 & 0,45 & 0,26 & 0,49 & 0,51 & חمח 2-0 \\
\hline & & Chuva & 0,50 & 0,43 & 0,58 & 0,57 & 0,29 & $0-2.000$ \\
\hline$T$ & $(\underline{0} \mathrm{C})$ & Seco & $23,55 \mathrm{c}$ & $25,92 \mathrm{a}$ & $24,58 \mathrm{~b}$ & $22,62 \mathrm{c}$ & $25,28 \mathrm{~b}$ & 18 ? 21 \\
\hline 1 & $(-\infty)$ & Chuva & $23,55 \mathrm{c}$ & $27,04 \mathrm{a}$ & $25,86 \mathrm{a}$ & $24,39 \mathrm{~b}$ & $25,79 a$ & $100<4$ \\
\hline C.T & (NMP/100 & Seco & $1.430 \mathrm{a}$ & $74 \mathrm{~b}$ & $353 b$ & $1.090 \mathrm{a}$ & $27 b$ & 1000 \\
\hline & $\mathrm{mL})$ & Chuva & $975 a$ & $100 \mathrm{~b}$ & $920 \mathrm{a}$ & 920 a & $82 \mathrm{~b}$ & 1.000 \\
\hline
\end{tabular}

Médias com as mesmas letras minúsculas na horizontal não diferem estatisticamente entre si pelo teste de Scott-Knott a 5\% entre os pontos para a mesma variável e letras minúsculas na vertical, para cada variável, não diferem estatisticamente entre si nos períodos pelo teste de Scott-Knott a 5\%. NQ: Não Quantificado; ns: Não significativo pelo teste Scott-Kontt a 5\%.

Fonte: elaborado pelos autores (2018). 
Observa-se pela Tabela 2 que o íon $\mathrm{Ca}^{2+}$ foi quantificado apenas no $\mathrm{P} 1$, sendo que nos demais pontos esse elemento está ausente ou em concentração abaixo do limite de quantificação da metodologia utilizada. No P1, embora as concentrações estejam muito abaixo do limite máximo para águas de irrigação, observa-se que a concentração de $\mathrm{Ca}^{2+}$ aumenta no período chuvoso, podendo ser reflexo do escoamento superficial da água da chuva.

Já o $\mathrm{Mg}^{2+}$, além do $\mathrm{P} 1$, foram detectadas concentrações muito baixas. Já nos pontos P4 e P5, apenas no período chuvoso. No $\mathrm{P} 1$, à semelhança do $\mathrm{Ca}^{2+}$, a concentração de $\mathrm{Mg}^{2+}$ aumenta significativamente no período chuvoso (Skott-Knott, $5 \%$ ), porém mantem-se muito abaixo do limite máximo considerado adequado para irrigação.

O íon $\mathrm{Na}^{+}$também se manteve em concentrações muito baixas em todas as avaliações com destaque para o P1, o qual apresentou as maiores concentrações, porém, diferentemente do $\mathrm{Ca}^{2+}$ e do $\mathrm{Mg}^{2+}$, a maior concentração foi detectada no período de estiagem. A menor concentração de $\mathrm{Na}^{+}$no período chuvoso pode refletir o efeito da água das chuvas na diluição da concentração desse elemento, cuja fonte de enriquecimento provável deve ser o material rochoso do subsolo. Nos pontos P3 e P5, no período seco, a metodologia empregada não detectou a presença de $\mathrm{Na}^{+}$ nas amostras.

A elevada concentração do $\mathrm{Na}^{+}$em relação às concentrações de $\mathrm{Ca}^{2+}$ e $\mathrm{Mg}^{2+}$ podem causar problemas na estruturação dos solos (SILVA et al., 2011), visto que o valor da RAS é inversamente proporcional ao da salinidade (CE). Até mesmo as águas de chuvas podem ocasionar problema para os solos com características de sodicidade, a menos que minerais solúveis de $\mathrm{Ca}^{2+}$ ou $\mathrm{Mg}^{2+}$ estejam presentes no perfil (RENGASAMY, 2016).

Em função da ausência de $\mathrm{Ca}^{2+}$ e/ou $\mathrm{Mg}^{2+}$ entre P2 a P5 o cálculo da RAS para esses pontos foi comprometido, por isso, apresenta-se RAS apenas para o P1 onde se observa valores muito baixos, mas estatisticamente diferente entre si sendo maior no período seco. Desse modo, fica claro que pela análise isolada da RAS, não se observa risco de sodicidade do solo provocado pela água de irrigação originário do P1. Para P2 a P5 recomenda-se monitoramento continuado com emprego de técnicas laboratoriais e equipamentos mais modernos e precisos.

Analogamente à RAS a Du GHF, devido à ausência de valores quantificados para $\mathrm{Ca}^{2+}$ e/ou $\mathrm{Mg}^{2+}$, foi calculada apenas para o ponto $\mathrm{P} 1$, de onde se extrai que a 
água nesse ponto é muito doce. Estatisticamente a Du GHF da água do P1 se difere entre os períodos, sendo mais doce no período seco. A ausência de concentrações quantificáveis de $\mathrm{Ca}^{2+}$ e $\mathrm{Mg}^{2+}$ impossibilitou o cálculo da Du GHF, mas não impede a interpretação de que neste caso a água é extremamente doce. Portanto, verifica-se que as águas dos mananciais da TIRF apresentam-se sem restrição para a irrigação apontando para baixo risco de entupimento de emissores devido à precipitação do carbonato de cálcio $\left(\mathrm{CaCO}_{3}\right)$, como relatado por Ribeiro, Paterniani e Coletti et al. (2008). Yanfang et al. (2015) demonstraram em laboratório o efeito da Du GHF da água de irrigação na obstrução de gotejadores. Os autores relataram que o efeito prático da Du GHF se manifesta com a diminuição da taxa de fluxo do emissor e em seu experimento verificaram redução média de vazão da ordem $85 \%$ com $100 \%$ de emissores entupidos para uma água com $500 \mathrm{mg} \mathrm{L}^{-1}$ de Du GHF, resultado que demonstra a importância dessa variável na caracterização da água de irrigação.

$O$ valor da CE considerado normal, nas condições brasileiras, para a irrigação está no intervalo de 0 a $3 \mathrm{dS} \mathrm{m}^{-1}$ (AYERS \& WESTCOT, 1991). Pelos resultados (Tabela 2) verifica-se que em todas as amostras da área de estudo os valores estiveram entre 0,002 a $0,064 d S ~^{-1}$, não revelando risco de salinidade.

Ainda em relação à CE observa-se (Tabela 2) que o $\mathrm{P} 1$ se destaca dos demais revelando diferença estatística significativa com valores mais elevados e ainda revela valores diferentes entre os períodos, com maior CE no período seco.

A RAS deve ser interpretada juntamente com a CE (ALMEIDA, 2010) e pelos resultados observa-se que há severo risco de redução da infiltração, uma vez que, a CE é inferior a 2,0 dS $\mathrm{m}^{-1}$ e o valor da RAS <3. Pelos mesmos dados, utilizando a classificando de Richards (1954), verifica-se que a água é do tipo C0 - S1, ou seja, com risco nulo de salinidade e baixo risco de sodicidade, resultado que aponta para a boa qualidade da água em relação à salinidade e sodicidade.

As medições mensais de $\mathrm{pH}$ ao longo de um ano revelaram 3 grupos distintos (Scott-Kontt, 5\%), com destaque para os pontos P3, P4 e P5 que apresentam diferença estatística entre si, mas semelhança entre os períodos em cada ponto. Nesses pontos os valores de $\mathrm{pH}$ medidos em ambos os períodos, ficaram abaixo do valor mínimo $(6,50)$ considerado ideal para água de irrigação. Além desses, o P2, no período chuvoso, também apresentou pH abaixo do recomendado.

Valores de $\mathrm{pH}$ discrepantes do recomendado são mais alarmantes no período seco, que é quando a irrigação é mais demanda e neste sentido maior atenção deve 
ser dada a P3, P4 e P5. O P1 apresentou pH adequado em ambos os períodos e com semelhança estatística.

Estudos confirmam que o $\mathrm{pH}$, nas águas brasileiras, varia na faixa de 4 a 9 (PARRON; MUNIZ; PEREIRA, 2011) e que ocorrências como as queimadas podem poluir e contaminar a água (PEREIRA, 2004) reduzindo o pH. No ano de 2016 houve um incêndio florestal de grandes proporções na região atingindo a TIRF, o que pode ter contribuído para acidificação da água no período chuvoso, exceto no P4. Situação diferente dessa foi observada por Piratoba et al. (2017) na área portuária de Barcarena-PA Brasil, revelando a diversidade de ocorrência de valores de $\mathrm{pH}$ em águas superficiais nas regiões equatoriais.

Nos pontos P3, P4 e P5 o pH médio ficou abaixo do limite recomendado para irrigação (6.5 a 8.4). Porém esse fato não significa que a água não possa ser utilizada para irrigação, apenas indica qualidade anormal e/ou a presença de um íon tóxico, devendo passar por uma adequação para que o seu uso não provoque corrosão de componentes metálicos do sistema de aplicação de água como reportado por Lira et al. (2015) e Silva et al. (2011), ou deve-se utilizar materiais resistentes à corrosão, como, por exemplo, o pvc ou polietileno. Resultado semelhante para a variável pH foi reportada por Andrietti et al. (2016) no rio Caiabi, municípios de Sinop e Vera, no estado do Mato Grosso/BR, evidenciando que as águas dos mananciais disponíveis na TIRF não diferem, em relação ao pH, da água de outras regiões do estado.

Ao analisar a variável Alc verifica-se que no P1 ela se destaca dos demais, se mostrando estatisticamente diferente e com valores mais elevados. Não há para nenhum dos pontos diferenças estatísticas entre períodos do ano, revelando águas homogêneas ao longo do ciclo hidrológico anual. Todos os valores de Alc estão muito abaixo da faixa considerada normal em águas naturais, que é de 30 a $500 \mathrm{mg}$ $\mathrm{L}^{-1}$ de $\mathrm{CaCO}_{3}$.

Os íons benéficos $\mathrm{N}, \mathrm{P}$ e $\mathrm{K}$, os quais são macro nutrientes agrícola, apresentaram concentrações muito baixas próximas de zero estando, portanto, muito abaixo do limite máximo considerado ideal para irrigação. Além disso, o teste estatístico não detectou diferenças significativas nas concentrações de $\mathrm{N}$ e $\mathrm{P}$ tanto entre pontos, quanto entre períodos. Isso revela homogeneidade de oferta de nutrientes ao longo do ciclo hidrológico refletindo na baixa capacidade de crescimento de organismos eutrofizantes, os quais podem danificar equipamentos de distribuição de água especialmente nos métodos de irrigação localizada. 
O ín $\mathrm{K}$ sempre está na água dos mananciais avaliados em concentrações baixas e não foi detectado nas amostras do P2 no período seco e no P5 em ambos os períodos. Esse resultado indica que as águas avaliadas podem estar sofrendo pouca ou nenhuma interferência exógena (SILVA et al., 2011).

Para os íons $\mathrm{Na}$ e $\mathrm{Cl}^{-}$os teores aferidos nas amostras são inferiores aos limites capazes de causar toxidade às plantas. Observa-se para esses íons que há diferença estatística entre períodos e entre pontos refletindo as características geológicas locais, bem como a variabilidade de solos e vegetação, como sugere (ALMEIDA, 2010). Todavia, embora tenham sido detectadas diferenças entre médias, as concentrações encontradas são consideradas normais conforme explica Dinka, Loiskandlb e Ndambukic (2015).

Destaca-se que, para $\circ \mathrm{Cl}^{-}$, as maiores concentrações foram encontradas no $\mathrm{P} 2$, diferentemente do que se observou para os demais elementos os quais se apresentaram com maiores concentrações no P1. Embora não haja diferença estatística para as concentrações de $\mathrm{Cl}^{-}$no ponto P2 entre os períodos avaliados, observa-se maior concentração numérica no período seco. Esse comportamento é semelhante ao que ocorre no P1 para $0 \mathrm{Na}$ indicando que 0 aporte desses elementos à água pode ter origem no manto rochoso do subsolo e que a água das chuvas pode estar diluindo-os diminuindo suas concentrações na água dos mananciais superficiais avaliados. Acrescenta-se ainda que, na área de estudo, há estados erosivos aparentemente naturais cujas características são de solos sódicos.

Para $\mathrm{O} \mathrm{HCO}_{3}^{-}$não há diferença entre períodos para cada curso d'água analisado. No entanto, o P1 se destaca dos demais com valores mais elevados. Todavia, observa-se que em todas as medições a concentração de $\mathrm{HCO}_{3}{ }^{-}$está próximo de zero e bem distante do valor máximo permitido, que é de $10 \mathrm{mg} \mathrm{L}^{-1}$.

Nos pontos avaliados nesta pesquisa verificou-se, para a variável Tu, valor médio máximo de 32,49 UNT e valores mais elevados durante o período chuvoso. Esse resultado reflete as condições locais de solo e escoamento superficial da água da chuva para os corpos hídricos contaminando-os com material particulado carreado da superfície do solo. De modo geral, a Tu não é um impedimento para irrigação com as águas dos mananciais estudados.

Embora os valores médios de Tu estejam baixos, vale destacar que, no P1 em uma das campanhas, a medição encontrou valor que ultrapassou o limite de 100 UNT, resultado este que pode estar relacionado ao material em suspensão nos corpos de água em períodos chuvosos, em que a concentração de sólidos em 
suspensão aumenta consideravelmente e pode contribuir para o entupimento de aspersores e danificar o equipamento (SILVA et al., 2011). Em situações de alta Tu constante a água deverá passar por filtragem a fim de evitar entupimentos de emissores de água.

Para a variável ST verificou-se (Tabela 2) que não detectou diferença significativa (Scott-Knott, 5\%) entre pontos ou períodos revelando uma água limpa com médias próximas de zero, valor este muito distante do máximo considerado alarmante para irrigação que é de $2.000 \mathrm{mg} \mathrm{L}^{-1}$. Esse resultado reflete os dados de Tu, os quais também foram baixos. Silva et al. (2011) relata que os sólidos em suspensão é um dos principais problemas da irrigação localizada provocando entupimento significativo de emissores. Quanto a esta variável verifica-se que não há qualquer limitação de uso da água dos mananciais da TIRF para irrigação, por qualquer método.

A T da água apresentou diversidade de comportamento entre pontos e entre os períodos do ano, formando 3 grupos distintos, com valores médios oscilando entre 22,62 e 27,04 ํ․ O P1 em ambos os períodos e o P4 no período seco apresentaram médias semelhantes (Scott-Knott, 5\%) e dentro do intervalo considerado adequado. Todos os demais pontos, nos dois períodos, apresentaram $T$ maior que $24 \stackrel{\circ}{ } \mathrm{C}$. Essas diferenças são, possivelmente, pela característica de solo e insolação conforme reportado por Vinaga et al. (2015) no Assentamento Vão Grande em Barra do Bugres/MT.

A T das águas indica influência nos processos de solubilidade (ALMEIDA, 2010) sendo que a faixa ideal para a irrigação está entre 18 e $24{ }^{\circ} \mathrm{C}$. Fora desse intervalo a T pode afetar a absorção dos nutrientes pela planta e acima desse valor, as águas com alto teor de $\mathrm{Ca}^{2+}$, podem formar incrustações danificando equipamentos (PEIXOTO et al., 2016). Assim, o P1, nos dois períodos, e o P4, no período seco, apresentaram os valores compatíveis.

Os resultados para C.T. variaram entre 27 e 1.430 NMP/100 mL revelando contaminação fecal em todos os pontos tanto no período seco quanto chuvoso, com diferenças estatísticas entre pontos e períodos. Os pontos P1 e P4 apresentaram as maiores médias com semelhança entre os períodos, mas com valores numericamente superiores no período seco. Já o P3 apresentou diferença entre os períodos com maior média no período chuvoso. Salienta-se que não há lançamento de esgoto no trecho avaliado podendo se explicar a presença de C.T. como de origem natural, possivelmente de animais silvestres ou exóticos (bovino). Em estudo 
realizado no rio La Paz (Bolívia) Poma, Mamani e Iñiguez (2016) relataram contaminação por C.T. de origem urbana, além de esterco bovino não tratado e a presença de animais selvagens.

De acordo com contagem de C.T. os pontos sem restrições para a irrigação são P2 e P5. O P3 pode ser utilizado com ressalva para irrigação de hortaliças consumidas cruas e frutas que se desenvolvem rente ao solo. Já os pontos P1 e P4 podem ter suas águas utilizadas para irrigação somente para culturas arbóreas, cerealíferas e forrageiras.

A diferença estatística do $\mathrm{P} 1$ com os demais pontos amostrados era esperada, pois não há proteção das Áreas de Preservação Permanente - APP nas margens desse manancial.

De modo geral, somente as variáveis Tu, C.T. são fatores limitantes para a irrigação enquanto que as demais variáveis refletem as condições dos solos álicos ou distróficos. O efeito combinado da CE e RAS também demonstra restrição em todos os pontos para o risco de redução da infiltração da água no solo. Os solos Neossolos Quartzarênicos ou areias quartzosas de cerrado, por onde a água percola, influencia a qualidade das águas, visto que acidez alta ou muito alta e os teores de $\mathrm{Ca}^{2+}, \mathrm{Mg}^{2+}, \mathrm{K}^{+}, \mathrm{Na}^{+}$e $\mathrm{P}$ são baixos, consequentemente, solos com baixa fertilidade (SPERA et al., 1999).

As culturas agrícolas desenvolvidas na TIRF fazem parte do contexto econômico para a geração de renda e oferta de alimentos na aldeia, são compostos por cultivares tradicionais e introduzidos, assim na Tabela 3 apresenta as variáveis restritivas e das culturas passíveis de irrigação.

Tabela 3 - Variáveis restritivas, cultivos nas roças e lavoura da TIRF

\begin{tabular}{|c|c|c|c|c|c|c|c|}
\hline \multirow{2}{*}{ Cultura } & \multirow{2}{*}{$\begin{array}{l}\text { Método (s) } \\
\text { de } \\
\text { irrigação }\end{array}$} & \multicolumn{6}{|c|}{ Restrição } \\
\hline & & CE & CE/RAS & $\mathrm{pH}$ & C.F. & Tu & $\mathrm{T}$ \\
\hline $\begin{array}{c}\text { Banana, } \\
\text { mandioca, batata } \\
\text { doce, cará da terra }\end{array}$ & $\begin{array}{l}\text { Superfície } \\
\text { Localizada }\end{array}$ & SR & $\mathrm{CR}$ & SR & SR & $\mathrm{CR} / \mathrm{P} 1$ & CR-P2/P3/P5 \\
\hline Milho & $\begin{array}{l}\text { Superfície } \\
\text { Localizada }\end{array}$ & SR & CR & CR-P3/P5 & SR & $\mathrm{CR} / \mathrm{P} 1$ & CR-P2/P3/P5 \\
\hline Soja & $\begin{array}{l}\text { Superfície } \\
\text { Localizada }\end{array}$ & SR & $\mathrm{CR}$ & CR-P3/P5 & SR & $\mathrm{CR} / \mathrm{P} 1$ & CR-P2/P3/P5 \\
\hline Arroz & $\begin{array}{l}\text { Superfície } \\
\text { Localizada }\end{array}$ & SR & $\mathrm{CR}$ & CR/P5 & SR & $\mathrm{CR} / \mathrm{P} 1$ & CR-P2/P3/P5 \\
\hline
\end{tabular}




\begin{tabular}{cccccccc}
\multirow{2}{*}{ Melância } & $\begin{array}{c}\text { Superfície } \\
\text { Localizada } \\
\text { Hortaliça folhosas }\end{array}$ & SR & CR & CR/P5 & SR & CR/P1 & CR-P2/P3/P5 \\
& $\begin{array}{c}\text { Superfície } \\
\text { Localizada }\end{array}$ & SR & CR & SR & $\begin{array}{c}\text { CR/P1 } \\
\text { /P3/P4 }\end{array}$ & CR/P1 & CR-P2/P3/P5 \\
\hline
\end{tabular}

SR: sem restrição; CR: com restrição; CR/: com restrição no ponto.

Fonte: Almeida (2010); Lopes (1998); Brasil (2005); Peixoto et al. (2016). Adaptado pelos autores.

Pelos dados da Tabela 3 observa-se que há algum tipo de restrição para todas as culturas. Todavia, esse resultado não significa inviabilidade do uso da água para irrigação, significa que há necessidade de acompanhamento técnico e emprego de equipamentos adequados para cada caso. Por exemplo, as restrições para Turbidez podem ser resolvidas com instalação de filtros. Já a temperatura elevada da água pode ser amenizada agendando os eventos de irrigação para as horas mais frescas do dia (início da manhã ou final da tarde) ou ainda à noite. A presença de coliformes restringe o uso da água apenas para irrigação de folhosas podendo ser utilizadas para as demais culturas. O efeito combinado da CE com a RAS revela risco de redução da infiltração no solo, requerendo maior atenção quanto a esse efeito.

\section{Conclusões}

A vazão outorgável, estimada pela regionalização hidrológica, disponível nos mananciais avaliados é de $1,884 \mathrm{~m}^{3} \mathrm{~s}^{-1}$ revelando oferta, não se caracterizando como uma limitação para implantação de sistemas de irrigação na TIRF, excetuando o P5 onde foi observado déficit. Contudo, para todas as bacias estudadas deverão ser feitos novos estudos mais completos e abrangentes.

Todos os corpos de água avaliados apresentaram boa qualidade de água para irrigação, mas o efeito combinado da CE e RAS revelou severo risco de redução da infiltração, sua utilização deve ser feita com acompanhamento técnico especializado e sem esse cuidado poderá apresentar processos erosivos.

Mesmo os corpos de água com baixo impacto exógeno se apresentaram impróprios para a irrigação de hortaliças folhosas que são consumidas cruas e frutas que se desenvolvem rentes ao solo e que são ingeridas cruas sem remoção de película (P1, P3 E P4) devido à presença de C.T. em alta concentração. Demais restrições para os cultivares da comunidade deverão ter acompanhamento técnico especializado.

Pela importância da Chapada dos Parecis para o agronegócio torna-se salutar a observação dos corpos de água quanto a sua condição para a irrigação, mesmo 
que sejam utilizadas águas naturais com vista a salvaguardar o patrimônio produtivo e o ambiente.

\section{Agradecimentos}

À Universidade do Estado de Mato Grosso - UNEMAT - Câmpus Universitário Dep. Est. Renê Barbour, por ter disponibilizado o laboratório para proceder as análises; ao Centro de Pesquisas, Estudos e Desenvolvimento AgroAmbientais - CPEDA pela utilização do Fotômetro de Chama ( $\mathrm{Na}$ e K) da UNEMAT Campus de Tangará da Serra/MT; ao CNPq pela avaliação de mérito científico da pesquisa em Terra Indígena, à comunidade indígena da Terra Indígena Rio Formoso por ter permitido a pesquisa no seu território, à FUNAI que autorizou e deu condições para que pudesse ser realizada, a SAMAE de Tangará da Serra/MT que disponibilizou o laboratório da ETA para eventuais análises.

\section{REFERÊNCIAS}

ALMEIDA, O. A. Qualidade da água de irrigação. Cruz das Almas: Embrapa Mandioca e Fruticultura, 2010.

ANDRIETTI, G. et al. Índices de qualidade da água e de estado trófico do rio Caiabi, MT. Rev. Ambient. Água. Taubaté, vol. 11, n 1, p 162-175, mar. 2016. DOI: 10.4136/ambiagua.1769

APHA. American Public Health Association. Standard methods for the examination ofwater and watwater, 21st ed. Washington, 2005.

AYERS, R. S.; WESTCOT, D. W. A qualidade da água na agricultura. Tradução de H. R. Gheyi, J. F. de Medeiros; F. A. V. Damasceno. Campina Grande: UFPB, 1991. 218p. (FAO. Estudos de Irrigação e Drenagem, 29 - revisado 1).

AZEVEDO NETTO, J. M. et al. Manual de Hidráulica. 8.ed. São Paulo, 1998. 670p.

BRASIL. Conselho Nacional de Meio Ambiente. Resolução CONAMA 357, de 17 de março de 2005. Disponível em: http://www2.mma.gov.br/port/conama/legiabre.cfm?codlegi=459. Acesso em: 3 out. 2017.

BORTOLINI, L.; MAUCIERI, C.; BORIN, M. A Tool for the Evaluation of IrrigationWater Quality in the Arid and Semi-Arid Regions. Agronomy, v.8, n.23, p. 1-15, 2018, DOI: 10.3390/agronomy8020023.

DALLACORT, R. et al. Wind speed and direction characterization in Tangará da Serra, Mato Grosso state, Brazil. Rev. bras. meteorol. São Paulo, v. 25, n. 3, p. 359-364, Sept. 2010. DOI:10.1590/S0102-77862010000300007.

DINKA, M. O.; LOISKANDLB, W.; NDAMBUKIC, J. M. Hydrochemical characterization of various surface water and groundwater resources available in Matahara areas, Fantalle Woreda of Oromiya region. Journal of Hydrology: Regional Studies. v.3, p. 444-456, Mar. 2015. DOI: 10.1016/j.ejrh.2015.02.007. 
FENNER, W. et al. Análise do balanço hídrico mensal para regiões de transição de Cerrado-Floresta e Pantanal, Estado de Mato Grosso. Acta Iguazu, v.3, p 72-85. 2014.

FUNAI, Fundação Nacional do Índio. Base de dados de geoprocessamento. Brasília, 2018. Disponível em: http://www.funai.gov.br/index.php/shape. Acesso em: 20 ago. 2018.

IBGE, Instituto Brasileiro de Geografia e Estatística. Geociências. Downloads. Organização do território, Divisão regional do Brasil, Divisão regional do Brasil em regiões geográficas 2017. Disponível em: https://www.ibge.gov.br/geociencias/downloads-geociencias.html. Acesso em: 09 mar. 2018.

IBGE. Indicadores IBGE. Estatística da Produção Agrícola, Rio de Janeiro, dez. 2019. Disponível em: https://biblioteca.ibge.gov.br/index.php/bibliotecacatalogo?view=detalhes\&id=72415. Acesso em: 12 jan. 2020.

INPE. Instituto Nacional de Pesquisas Espaciais. Divisão de Sensoriamento Remoto (DSR). Topodata: Banco de Dados Geomorfométricos do Brasil. São Paulo: INPE; DSR, 2018. Disponível em: http://www.webmapit.com.br/inpe/topodata/. Acesso em: 03 fev. 2018.

LIRA, R. M. et al. A utilização de águas de qualidade inferior na agricultura irrigada | The use of lower quality water in irrigated agriculture.Revista Geama, [S.I.], p. 341-362, abr. 2016. ISSN 2447-0740.

LOPES, A.S. Manual internacional de fertilidade do solo. Tradução e Adaptação. 2.ed. Piracicaba, Potafos, 1998. 177p.

MATO GROSSO. Secretaria de Meio Ambiente. Sistema Integrado de Monitoramento e Licenciamento Ambiental. Outorga, Consultar Disponibilidade Hídrica. 2018. Disponível em https://monitoramento.sema.mt.gov.br/simlam/, acesso em 03/03/2018.

QUEIROZ, T. M.; MELO, M. T.; FERREIRA, F. S. Qualidade da água para irrigação na comunidade quilombola vão grande, município de Barra do Bugres/MT. Revista Brasileira da Agricultura Irrigada, v.12, n.3, p. 2613-2620, 2018. DOI: 10.7127/rbai.v12n300733

PARRON, L. M.; MUNIZ, H. F.; PEREIRA, C. M. Documentos 232: Manual de procedimentos de amostragem e análise físico-química de água. Colombo: Embrapa Florestas, 2011. $67 \mathrm{p}$.

POMA, V.; MAMANI, N.; IÑIGUEZ, V. Impact of urban contamination of the La Paz River basin on thermotolerant coliform density and occurrence of multiple antibiotic resistant enteric pathogens in river water, irrigated soil and fresh vegetables. SpringerPlus, v 5, n. 499, 2016. DOI: 10.1186/s40064-016-2132-6.

PEIXOTO, S. C. et al. Avaliação da qualidade da água na região de Santa Maria. Ciência e Natura, [SI], v. 38, n. 1, p. 443 - 452, jan. 2016. DOI: 10.5902/2179460X19756.

PEREIRA, R. S. Poluição Hídrica: Causas e Consequências. Revista Eletrônica de Recursos Hídricos. IPH-UFRGS. v.1, n. 1, p. 20-36. 2004.

PIRATOBA, A. R. A. et al. Caracterização de parâmetros de qualidade da água na área portuária de Barcarena, PA, Brasil. Rev. Ambient. Água. v. 12 n. 3 Taubaté. 2017. DOI: 10.4136/ambi-agua.1910.

OLIVEIRA, J. R.; DERLAN, T. M.; QUEIROZ, T. M. Comparação entre vazões estimadas e medidas: um estudo para a bacia hidrográfica do rio Branco/MT. Revista Ibero-Americana de Ciências Ambientais, v.9, n.3, p.136-148, 2018. 
RAMOS, H. C. et al. Precipitação e temperatura do ar para o estado de Mato Grosso utilizando krigagem ordinária. Revista Brasileira de Climatologia, [S.I.], v. 20, ago. 2017. ISSN 2237-8642. DOI:10.5380/abclima.v20i0.43762.

RENGASAMY, P. Salt-affected soils in Australia. School of Agriculture, Food and Wine, University of Adelaide. 2016. 64p.

REIS, C. R. et al. Avaliação da qualidade da água para irrigação em Salto do Lontra - PR. Engenharia Ambiental, v.8, n.1, p.069-078, jan./mar. 2011.

REIS J. et al. Integração Lavoura-Pecuária-Floresta no Brasil. Sustentabilidade em Debate, v. 7, n. 1, p. 58 - 73, 30 abr. 2016. DOI:10.18472/SustDeb.v7n1.2016.18061.

RIBEIRO, T. A. P.; PATERNIANI, J. E. S.; COLETTI, C. Chemical treatment to unclogg dripper irrigation systems due to biological problems. Scientia Agrícola, v.65, n.1, p.1-9, 2008.

RICHARDS, L. A. Diagnosis and improvement of saline and alkali soils. Washington, D.C.: U.S. Salinity Laboratory. 1954, 160p.

SANTOS, E. D. et al. A criança indígena e as causas de mortalidade: Revisão integrativa. Scientia Amazonia, v. 7, n.1, p. 28-36, 2018.

SANTOS, J. QGIS 2.8 Delimitação de Bacias Hidrográficas com TauDEM, Processamento Digital Geotecnologias e Software Livre, Brasília-DF. Disponível em: http://processamentodigital.com.br/2017/11/06/qgis28-delimitacao-de-bacias-hidrograficascom-taudem/. Acesso em 11 de novembro de 2018.

SEIVA. Relatório de Impacto Ambiental - RIMA. Complexo Hidrelétrico Formoso. Capitulo IV. Diagnóstico do Meio Abiótico. Recursos Hídricos. Hidrologia Superficial. CuiabáMT: Brennand Energia - Seiva Engenharia e Projetos Ambientais Ltda. 2017.

SIEBERT, D. E.; VECCHIATO, A. B.; FERNANDO, X. T. S. Descrição do Uso e Ocupação da Cabeceira do Rio Jauru (MT) e Caracterização dos Processos de Degradação Ambiental. Scientific Journal Eng. and Science - UFMT, v. 1, ed. 1, 2014. DOI: 10.18607/ES201411608.

SILVA, I. N. et al. Qualidade de água na irrigação. ACSA - Agropecuária Científica no Semi-Árido, Campina Grande - PB, v.07, n. 3, p. 01-15, 2011. DOI: 10.30969/acsa.v7i3.134.

SILVEIRA, G. L.; TUCCI, C. E. M.; SILVEIRA, A. L. L. Quantificação de vazão em pequenas bacias sem dados. Revista Brasileira de Recursos Hídricos, v.3, n.3, p.111-131, 1998. DOI: 10.21168/rbrh.v3n3.p111-131

SPERA, S. T. et al. Solos areno-quartzosos do Cerrado: características, problemas e limitações ao uso. Planaltina: Embrapa CPAC. 1999. 48p.

TERÇAS, A. C. P. et al. Os Haliti-Paresí: uma reflexão sobre saúde e demografia da população residente nas terras indígenas Paresí. Espaço Ameríndio, Porto Alegre, v. 10, n.1, p. 226-253. 2016. DOI: 10.22456/1982-6524.60301.

VASCONCELO, R. S. et al. O. Qualidade da água utilizada para irrigação na extensão da microbacia do baixo Acaraú. Revista Brasileira da Agricultura Irrigada, v. 3, n. 1, p. 30-38, 2009. DOI: 10.7127/rbai.v3n100014 
VINAGA, L. et al. Caracterização físico-química da água utilizada pela população do Assentamento Quilombola Vão Grande - MT. Acta Iguazu, Cascavel, v.4. n. 2. P. 30-44. 2015.

YANFANG, L. et al. Effect of water hardness on emitter clogging of drip irrigation. Transactions of the Chinese Society of Agricultural Engineering, v. 31, n. 20, p. 95-100, 2015. DOI: 10.11975/j.issn.1002-6819.2015.20.014

\section{NOTAS DE AUTOR}

\section{CONTRIBUIÇÃO DE AUTORIA}

Martins Toledo de Melo - Concepção. Coleta de dados, Análise de dados, Elaboração do manuscrito, revisão; Participação ativa da discussão dos resultados.

Tadeu Miranda de Queiroz - Orientação. Participação ativa da discussão dos resultados; Revisão e aprovação da versão final do trabalho.

\section{FINANCIAMENTO}

Não se aplica.

\section{CONSENTIMENTO DE USO DE IMAGEM}

Não se aplica

\section{APROVAÇÃO DE COMITÊ DE ÉTICA EM PESQUISA}

Não se aplica.

\section{CONFLITO DE INTERESSES}

Não há

\section{LICENÇA DE USO}

Este artigo está licenciado sob a Licença Creative Commons CC-BY. Com essa licença você pode compartilhar, adaptar, criar para qualquer fim, desde que atribua a autoria da obra.

\section{HISTÓRICO}

Recebido em: 11-05-2019

Aprovado em: 18-02-2020 